\title{
Fabrication and Application of Molybdenum Trioxide Nanostructure Materials for Electrochemical Capacitors
}

\author{
Fengjuan Miao ${ }^{1, *}$, Wenyi $W u^{1}$, Qianqian $\mathrm{Li}^{1}$, Rui Miao ${ }^{1}$, Bairui Tao ${ }^{1,2 *}$ \\ ${ }^{1}$ College of Communications and Electronics Engineering, Qiqihar University, Heilongjiang 161006, \\ China \\ ${ }^{2}$ Modern Education Technology Center, Qiqihar University, Heilongjiang 161006, China \\ E-mail: miaofengjuan@163.com, tbr_sir@163.com
}

doi: $10.20964 / 2017.12 .200$

Received: 28 July 2016 / Accepted: 5 June 2016 / Published: 12 November 2016

In this paper, a new method of "top-down" metal-assisted chemical wet etching to fabricate $\mathrm{MoO}_{3}$ nanostructure materials is put forward for the first time by the authors, which overcomes the weakness such as complex technology and high cost. In the solution system of $\mathrm{AgNO}_{3} / \mathrm{HNO}_{3}$, the fabrication of $\mathrm{MoO}_{3}$ nanostructure materials is conducted under certain conditions and then the samples are annealled under high temperature as $500-700{ }^{\circ} \mathrm{C}$. Observed by scanning electron microscope ( SEM ), when the concentration of $\mathrm{AgNO}_{3}$ is $0.01 \mathrm{M}, \mathrm{HNO}_{3}$ solution concentration as $3.6 \mathrm{M}$, the temperature as $(20 \pm 2)^{\circ} \mathrm{C}$, the etching time as $90 \mathrm{~min}$, the anneal temperature as $600{ }^{\circ} \mathrm{C}$, the fabricated $\mathrm{MoO}_{3}$ nanostructure materials has well morphology. In $0.5 \mathrm{M} \mathrm{Na}_{2} \mathrm{SO}_{4}$ solution, the sample electrode $\left(600{ }^{\circ} \mathrm{C}\right)$ shows a higher capacitance of $30.85 \mathrm{~F} \mathrm{~g}^{-1}$ at $10 \mathrm{mV} / \mathrm{s}$. The method above to fabricate $\mathrm{MoO}_{3}$ owns the superiority such as simple, low cost and easy to control the reaction process, so it will be popularized for large-scale fabrication of $\mathrm{MoO}_{3}$ nanostructure materials.

Keywords: Molybdenum trioxide nanostructure materials; Metal-assisted chemical etching; Top-down method; Electrochemical capacitors

\section{$\underline{\text { FULL TEXT }}$}

(C) 2017 The Authors. Published by ESG (www.electrochemsci.org). This article is an open access article distributed under the terms and conditions of the Creative Commons Attribution license (http://creativecommons.org/licenses/by/4.0/). 